\title{
Dố fl|MA
}




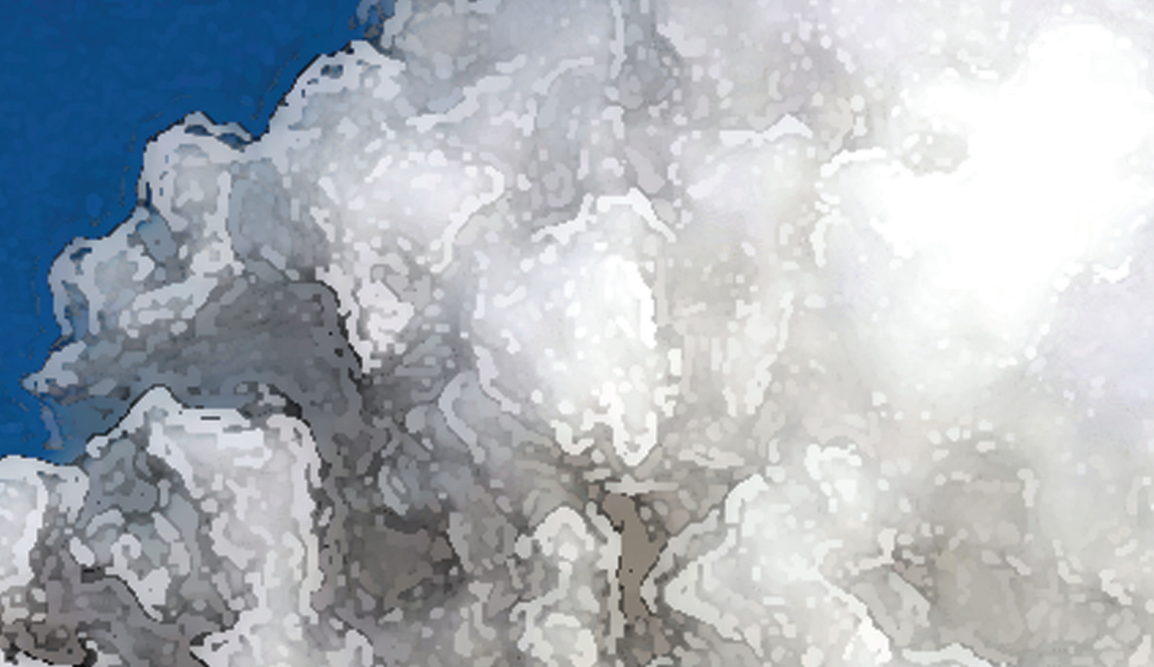

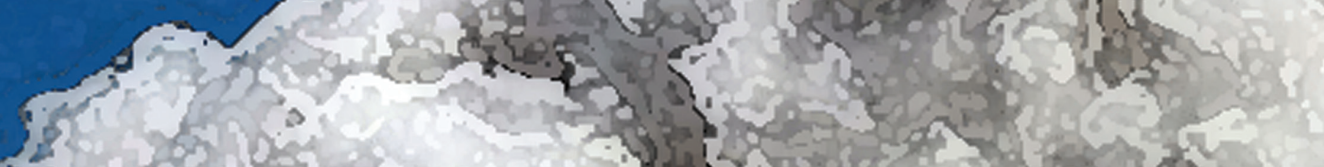

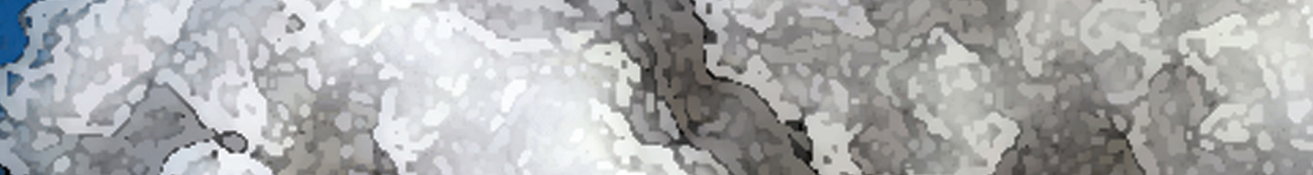

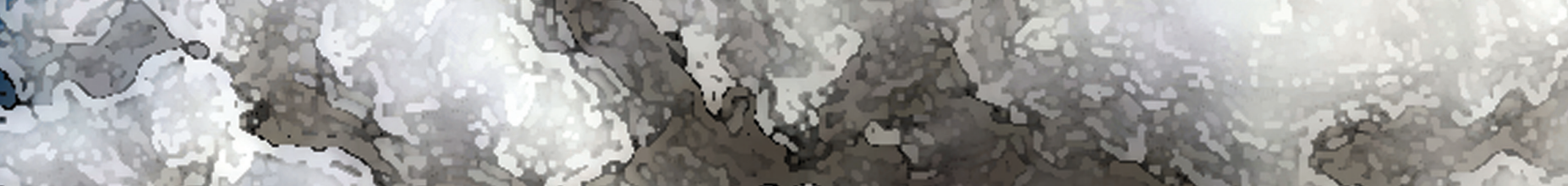

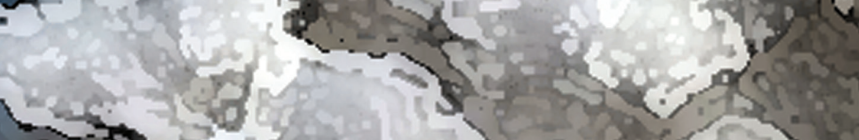

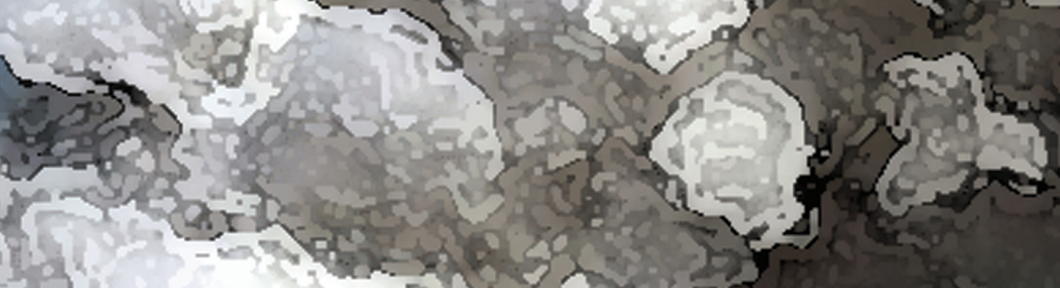

(i)

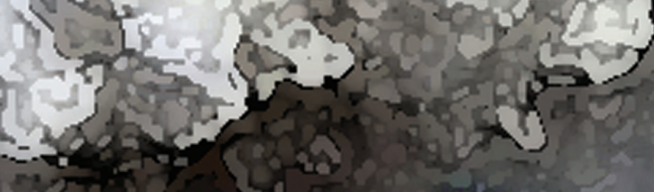

a. ande

at $x$ sent

H the

10 is

$3 x_{1}+x^{2}$

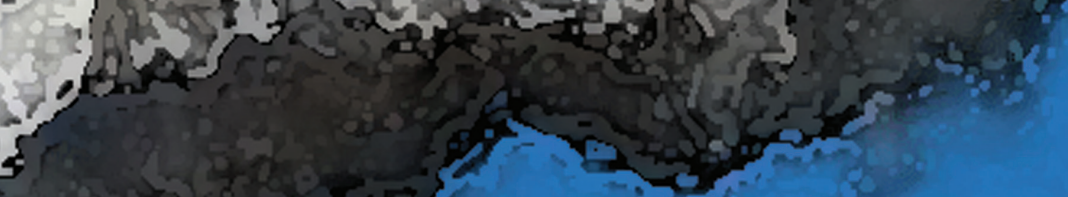

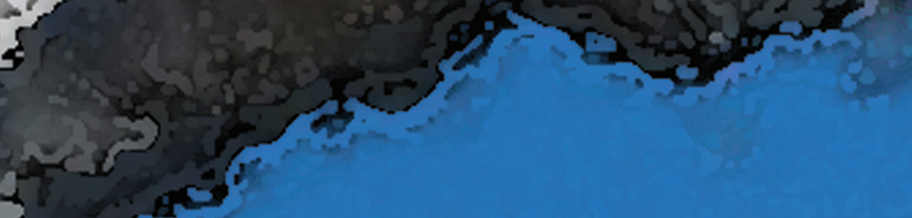




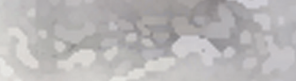




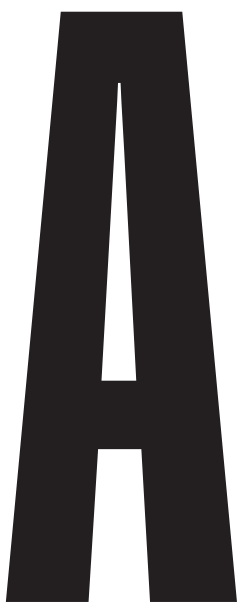

s mudanças no clima de nosso planeta já estão em andamento e estão tendo efeitos importantes sobre os ecossistemas e a nossa organização socioeconômica. O aumento de temperatura já observado (desde 1850 a 2010) de 1 grau centígrado, em média, em todo o planeta, e de 1,5 grau, no Brasil, está acarretando efeitos ambientais importantes. Observações sobre alterações biológicas, como migrações, decréscimo de população de espécies, intensificação de furacões e tornados, entre tantos efeitos, estão sendo analisadas com uma frequência incomum. A ciência avança rápido nessa área, com novas observações importantes o tempo todo, e com melhorias constantes nos modelos climáticos. Não temos muito tempo para iniciar um forte programa de redução de emissões de gases de efeito estufa se quisermos evitar um aquecimento médio maior que 2 graus centígrados na Terra. Do ponto de vista científico, nosso conhecimento sobre o funcionamento do sistema terrestre cresceu muito nas últimas décadas, graças ao esforço de milhares de cientistas. O Painel Intergovernamental sobre Mudanças Climáticas (IPCC, da sigla em inglês) compila, a cada quatro ou cinco anos, o conhecimento científico gerado por milhares de cientistas de todas as áreas. Esse esforço tem sido incorporado nos modelos climáticos, que são muito mais completos hoje do que há cinco ou dez anos. As dinâmicas interações entre a atmosfera, a biosfera, a hidrosfera, a criosfera e a geosfera mostram um planeta agindo como um sistema complexo, em permanente mudança.

A espécie humana adquiriu a propriedade de, através da queima de combustíveis fósseis, alterar a composição da atmosfera. Observamos grandes alterações nas concentrações atmosféricas de $\mathrm{CO}_{2}$ (dióxido de carbono), $\mathrm{CH}_{4}$ (metano), $\mathrm{N}_{2} \mathrm{O}$ (óxido nitroso), $\mathrm{O}_{3}$ (ozônio), aerossóis e nuvens, entre outras alterações. Mas, fundamentalmente, estamos alterando o balanço radiativo de nosso planeta, que controla o fluxo de radiação solar que entra no sistema terrestre e o fluxo de calor que é irradiado de volta ao espaço. Para manter a vida na Terra, recebemos, em média, $340,2 \mathrm{~W} / \mathrm{m}^{2}$ de energia do sol. A redistribuição desse calor pela atmosfera e pelos oceanos gera a circulação atmosférica e oceânica. $\mathrm{Na}$ atmosfera, o transporte de vapor de água alimenta o ciclo hidrológico, muito importante para a produção agrícola, por exemplo. Nos modelos climáticos, levamos em conta a componente física do clima, mas muito pouco da química e da biologia do planeta. Afinal, vivemos em um planeta no qual a biologia da vida exerce papel fundamental na manutenção do clima, através da função regulatória da vegetação, da biologia dos oceanos e das atividades dos seres vivos em geral, incluindo nós.

Através das atividades humanas, estamos injetando anualmente 9 milhões de toneladas adicionais de carbono fóssil na atmosfera. A concentração de $\mathrm{CO}_{2}$ aumentou de $280 \mathrm{ppm}$ para $400 \mathrm{ppm}$ desde 1750 . Desse total emitido para a atmosfera, 
$27 \%$ estão sendo absorvidos pelos oceanos, causando rápida acidificação. Cerca de $28 \%$ estão sendo absorvidos pelos ecossistemas terrestres. A diferença entre as emissões antropogênicas e a absorção de $\mathrm{CO}_{2}$ pelos ecossistemas terrestres e aquáticos, que corresponde a $45 \%$, está ficando na atmosfera, causando o aumento da concentração de $\mathrm{CO}_{2}$ atmosférico. Entre outras mudanças que o homem está realizando na Terra estão as alterações do uso do solo, pelo desenvolvimento da agricultura e de atividades humanas, e a do albedo da superfície terrestre, que é a fração da radiação refletida de volta ao espaço. Isso também altera o balanço radiativo que controla a temperatura do planeta.

Os efeitos das atividades antropogênicas nos ecossistemas terrestres são muitos, e vão desde o nível do mar subindo, o derretimento de geleiras, a perda de gelo no Oceano Ártico, as alterações biológicas em migrações de espécies, a acidificação dos oceanos e assim por diante. Estamos mudando a face de nosso planeta, em processos que a ciência ainda não conhece por inteiro.

Embora a atribuição às mudanças climáticas globais de eventos climáticos extremos particulares (uma chuva forte, uma seca intensa, etc.) ainda não seja possível, a estatística deixa muito claro que estamos tendo mais eventos climáticos extremos em todo o planeta. De acordo com compilação do IPCC Special Report on Climate Extremes, temos cerca de oito vezes mais extremos climáticos na última década se comparado com a década de 50 do século passado. Esses eventos extremos, como o atual período de seca na região metropolitana de São Paulo e no Nordeste, além das secas na Amazônia em 2005 e 2010, têm fortes impactos sociais e econômicos.

Se quisermos garantir às novas gerações um clima adequado para agricultura, vida urbana, produção de hidroeletricidade, etc., precisaremos estabilizar as concentrações de $\mathrm{CO}_{2}$, que, atualmente, estão em 400 ppm. Os cenários de emissões indicam que, na trajetória de emissões atuais, chegaríamos em 2100 com concentrações de $\mathrm{CO}_{2}$ da ordem de 800 ppm, com um aumento médio de temperatura de 6 a 7 graus centígrados, e algumas regiões como o Ártico aquecendo-se em 10 a 12 graus. Tal cenário é impensável hoje, mas é o que nos aguarda se não reduzirmos fortemente as emissões para que possamos atingir uma concentração de $\mathrm{CO}_{2}$ ao nível de 350 ppm (mais baixa do que temos hoje). Para isso, teríamos que cortar $80 \%$ das emissões ainda nesta década, visando a uma futura estratégia de emissões negativas, ou seja, que o sistema terrestre tenha mais absorção de carbono do que emitimos pelas atividades humanas.

Uma das grandes questões a enfrentar é o crescimento populacional, já que somos cerca de 7 bilhões de pessoas, com nível de consumo em constante aumento. Uma estrutura econômica que é baseada em crescimento econômico permanente evidentemente não é sustentável, pois os recursos naturais do planeta são finitos, e alguns deles, escassos. A questão da disponibilidade de água, por exemplo, está crítica em várias partes, e seu uso crescente, especialmente na agricultura e em áreas urbanas, é difícil de ser sustentável.

Uma nova alternativa à mitigação de emissão de gases de efeito estufa é a redução dos chamados poluentes de meia-vida curta (SLCP - short lived climate pollutants). Esses compostos são principalmente o metano $\left(\mathrm{CH}_{4}\right)$, o ozônio $\left(\mathrm{O}_{3}\right)$ e o chamado black carbon (BC). $\mathrm{O}$ gás metano é cerca de 23 vezes mais eficiente para fazer efeito estufa por molécula do que o $\mathrm{CO}_{2}$, e tem meia-vida de cerca de 12 anos. Portanto, a redução de emissões de metano tem um impacto no clima mais rápido do que reduções nas emissões de $\mathrm{CO}_{2}$, que tem meia-vida atmosférica dependente do processo de absorção, que vai de 100 a 10.000 anos. As emissões de metano ocorrem principalmente na agricultura, na criação de gado, na exploração de petróleo e gás, nas queimadas e em outros processos. $\mathrm{O}$ ozônio, além de ser um forte gás de efeito estufa, é um poderoso poluente em áreas urbanas, tendo fortes efeitos deletérios sobre a saúde da população urbana. O ozônio é produzido secundariamente na atmosfera a partir de emissões de hidrocarbonetos e óxidos de nitrogênio. O chamado black carbon consiste em partículas emitidas em processos de queima de combustíveis (fósseis, madeira, ou qualquer outro), como por exemplo pelo cano de descarga de veículos a diesel (ônibus e caminhões).

A queima de lenha para cozinhar e para aquecimento em países em desenvolvimento também é uma importante fonte de black carbon para a atmosfera. O black carbon e o ozônio têm meia-vida de alguns dias na atmosfera, portanto, a redução de sua emissão tem efeito forte e rápido. Além 
disso, a população urbana que sofre pelos efeitos da exposição a esses poluentes terá uma vida mais saudável. Os cobenefícios de redução de $\mathrm{CH}_{4}, \mathrm{O}_{3} \mathrm{e}$ black carbon no clima e na poluição do ar tornam esses poluentes agentes prioritários na mitigação das emissões, além das necessárias reduções nas emissões de $\mathrm{CO}_{2}$ pela queima de combustíveis fósseis. No longo prazo, o que domina a forçante radiativa global é a concentração de $\mathrm{CO}_{2}$, mas uma ajuda a curto prazo certamente é bem-vinda com a redução na emissão dos SLCP, com importantes benefícios na redução de poluição do ar tanto em áreas urbanas quanto nas áreas rurais.

Nosso país precisa se preparar melhor para a mitigação dos efeitos das mudanças climáticas e para a adaptação a elas. Seus impactos serão muito grandes em alguns setores econômicos, como a agricultura, ou na geração de hidroeletricidade, por exemplo. A Embrapa está trabalhando para o desenvolvimento da agricultura de baixo carbono, mas o esforço tem que englobar todos os setores econômicos brasileiros. Ações de adaptação nas áreas costeiras, com maior incidência de erosão devido ao aumento do nível do mar, e nas áreas urbanas e encostas, com o aumento da incidência de chuvas fortes, são necessárias e urgentes.

É fundamental que na próxima reunião da Conferência das Partes (COP-21), que ocorrerá em dezembro de 2015, em Paris, sejam assinados acordos internacionais que limitem em $80 \%$ as emissões de $\mathrm{CO}_{2}$ até 2030 ou 2040. Essa redução não será uma tarefa fácil, mas é essencial se quisermos estabilizar o clima de nosso planeta. A questão não é tecnológica, já que há alternativas à geração de eletricidade por meios renováveis (hidroeletricida- de, energia solar e eólica, por exemplo). Também há muito espaço para melhorar a eficiência no uso de energia nas indústrias e no setor de transporte, com automóveis mais eficientes e transporte público de massa nos grandes centros urbanos. É importante mencionar que já existe tecnologia para dobrar a eficiência de motores de combustão interna, como o dos automóveis.

Todavia, nem no Brasil nem em termos globais temos ainda políticas públicas efetivas para a implementação da necessária redução de emissões. A crise econômica global, que está se estendendo há vários anos, dificulta a implantação de economias de baixo carbono, mas, se quisermos uma economia sustentável a médio e longo prazo, não há outro caminho. $\mathrm{O}$ que na verdade está faltando é um sistema de governança global que possa gerenciar uma economia globalizada, seguindo os interesses não de grupos, países ou setores econômicos individuais, mas do planeta como um todo. Essa governança global é essencial para que um novo acordo climático seja implementado eficazmente.

Neste dossiê da Revista USP, abordamos alguns aspectos recentes da questão das mudanças climáticas globais. Os artigos lidam com a questão dos extremos climáticos, do papel dos oceanos regulando o clima de nosso planeta, da evolução dos modelos climáticos, do futuro climático do Brasil, do papel do vapor de água no clima da Terra e da introdução de uma nova era geológica, o Antropoceno.

Paulo Artaxo 